\title{
Reassurance of patients with cancer on cancer care continuum: a vital strategy to prevent anxiety of COVID-19 collateral damage
}

\author{
Deniz Can Guven ${ }^{1}$ (1)
}

Received: 21 February 2021 / Accepted: 19 April 2021 / Published online: 26 April 2021

(c) The Author(s), under exclusive licence to Springer-Verlag GmbH Germany, part of Springer Nature 2021

I read with great interest the remarkable study by Miaskowski et al. [1] evaluating oncology patients' perceptions and experiences with COVID-19. They reported a good level of COVID-19 knowledge and good compliance to COVID-19 precautions in their cohort. However, a significant rate of COVID-19 contraction fear and the fear of poor outcomes in COVID-19 was concerning. A significant portion of the patients anticipated a low likelihood of survival after COVID-19 contraction [1].

Although it was not evaluated in the present study, besides contracting the infection, a significant rate $(61 \%)$ of cancer patients was concerned about the cancer care disruptions due to COVID-19 in our previous study [2]. A similar finding was noted in a recent study by Colomer-Lahiguera et al. [3] showing the impact of COVID-19 on cancer care among main discussion points in the public online forums of patients with cancer. While all of our patients were under active treatment [2], only $27.6 \%$ of the patients were under active treatment in the present study [1]. Whether the rates of COVID-19-related cancer care disruption fear are different in patients under treatment or follow-up should be evaluated. Additionally, the outcomes of COVID-19 contraction and COVID-19-related cancer care disruption concerns were not thoroughly evaluated in the previous studies [1-3]. Whether these concerns lead to increased rates of psychological problems like depression, anxiety, and sleep problems should be evaluated in future studies.

The disruptions of cancer care during the pandemic, collateral damage, could affect all cancer domains, including screening and diagnosis, treatment, and palliative services. This collateral damage could take back the significant improvements in cancer outcomes, as evidenced by the UK model pointing out around $10 \%$ of additional cancer deaths

Deniz Can Guven

denizcguven@hotmail.com

1 Department of Medical Oncology, Hacettepe University Cancer Institute, 06100 Sihhıye, Ankara, Turkey in the following 5 years due to the pandemic [4]. Even after we can see the light at the end of the tunnel thanks to vaccines, the collateral damage to cancer care could continue till we return to normal. The possibility of continuing care disruptions could create significant and long-lasting anxiety burden for all patients with cancer, and even for the general population with cancer screening indications.

The oncology society has been very aware of the collateral damage risk of COVID-19, and oncological societies like ESMO published position papers to guide risk mitigations of care disruptions [5]. Additionally, flexible adaptations like telemedicine and clean hospitals aided to cancer care continuum [6,7]. Although there is a global and dedicated effort in the oncology community to ensure the continuum of cancer care during pandemic, patient education efforts seem to lag, preventing the patient reassurance and causing a greater anxiety burden. As previously stated, the negative feedback loop created by the infodemic and negativity on social media platforms could increase mental health problems $[8,9]$. So, there are novel patient education and information approaches like interactive online forums and easily accessible live streams by oncology communities and emphasizing the holistic nature of COVID-19 fight to return to normal in healthcare domains rather than disseminating information solely about COVID-19 prevention and COVID-19 care. With the aid of more organized patient education and reassurance efforts about the collateral damage of COVID-19 on cancer care, we could better protect our patients' mental health and quality of life during these times of uncertainty.

Author contribution DCG planned the work and conducted the review of relevant literature, drafted the manuscript, and reviewed and revised the final draft. DCG is responsible for the overall content as guarantor.

Data availability N/A. 
Code availability N/A.

\section{Declarations}

Ethics approval and consent to participate All procedures performed in studies involving human.

participants were in accordance with the ethical standards of the institutional and/or national research committee and with the 1964 Helsinki Declaration and its later amendments or comparable ethical standards.

\section{Consent to participate N/A.}

Consent for publication N/A

Conflict of interest The author declares no competing interests.

\section{References}

1. Miaskowski C, Paul SM, Snowberg K, Abbott M, Borno H et al (2021) Oncology patients' perceptions of and experiences with COVID-19. Support Care Cancer 29:1941-1950. https://doi.org/ 10.1007/s00520-020-05684-7

2. Guven DC, Sahin TK, Aktepe OH, Yildirim HC, Aksoy S et al (2020) Perspectives, knowledge, and fears of cancer patients about COVID-19. Front Oncol 10:1553-1553. https://doi.org/10.3389/ fonc. 2020.01553

3. Colomer-Lahiguera S, Ribi K, Dunnack HJ, Cooley ME, Hammer MJ (2021) et al. Experiences of people affected by cancer during the outbreak of the COVID-19 pandemic: an exploratory qualitative analysis of public online forums. Support Care Cancer 1-7. https://doi.org/10.1007/s00520-021-06041-y

4. Maringe C, Spicer J, Morris M, Purushotham A, Nolte E et al (2020) The impact of the COVID-19 pandemic on cancer deaths due to delays in diagnosis in England, UK: a national, populationbased, modelling study. Lancet Oncol 21:1023-1034. https://doi. org/10.1016/S1470-2045(20)30388-0

5. Curigliano G, Banerjee S, Cervantes A, Garassino M, Garrido P et al (2020) Managing cancer patients during the COVID-19 pandemic: an ESMO multidisciplinary expert consensus. Ann Oncol $31: 1320-1335$

6. Guven DC, Aktas BY, Aksun MS, Ucgul E, Sahin TK et al (2020) COVID-19 pandemic: changes in cancer admissions. BMJ Support Palliat Care. https://doi.org/10.1136/bmjspcare-2020-002468

7. Karacin C, Acar R, Bal O, Eren T, Sendur MAN et al (2021) "Swords and shields" against COVID-19 for patients with cancer at "clean" and "pandemic" hospitals: are we ready for the second wave? Support Care Cancer. https://doi.org/10.1007/ s00520-021-06001-6

8. Su Z, McDonnell D, Wen J, Kozak M, Abbas J et al (2021) Mental health consequences of COVID-19 media coverage: the need for effective crisis communication practices. Glob Health 17:4. https://doi.org/10.1186/s12992-020-00654-4

9. Sacerdote B, Sehgal R, Cook M Why is all COVID-19 news bad news? In National Bureau of Economic Research 2020.

Publisher's note Springer Nature remains neutral with regard to jurisdictional claims in published maps and institutional affiliations. 